\title{
Precipitation observation using microwave backhaul links in the alpine and pre-alpine region of Southern Germany
}

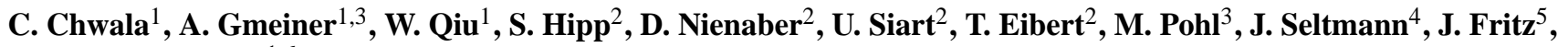 \\ and H. Kunstmann ${ }^{1,6}$ \\ ${ }^{1}$ Karlsruhe Institute of Technology (KIT), Institute for Meteorology and Climate Research (IMK-IFU), \\ Garmisch-Partenkirchen, Germany \\ ${ }^{2}$ Technische Universität München, Institute for High-Frequency Engineering, Munich, Germany \\ ${ }^{3}$ University of Applied Sciences Regensburg, Regensburg, Germany \\ ${ }^{4}$ Deutscher Wetterdienst, Hohenpeißenberg, Germany \\ ${ }^{5}$ Ericsson GmbH, Düsseldorf, Germany \\ ${ }^{6}$ University of Augsburg, Institute for Geography, Augsburg, Germany
}

Correspondence to: H. Kunstmann (harald.kunstmann@kit.edu)

Received: 23 December 2011 - Published in Hydrol. Earth Syst. Sci. Discuss.: 13 January 2012

Revised: 16 July 2012 - Accepted: 16 July 2012 - Published: 13 August 2012

\begin{abstract}
Measuring rain rates over complex terrain is afflicted with large uncertainties, because rain gauges are influenced by orography and weather radars are mostly not able to look into mountain valleys. We apply a new method to estimate near surface rain rates exploiting attenuation data from commercial microwave links in the alpine region of Southern Germany. Received signal level (RSL) data are recorded minutely with small data loggers at the towers and then sent to a database server via GSM (Global System for Mobile Communications). Due to the large RSL fluctuations in periods without rain, the determination of attenuation caused by precipitation is not straightforward. To be able to continuously process the RSL data from July 2010 to October 2010, we introduce a new method to detect wet and dry periods using spectral time series analysis. Its performance and limitations are presented, showing that the mean detection error rates of wet and dry periods can be reduced to $10 \%$ for all five links. After, the wet/dry classification rain rates are derived from the RSL and compared to rain gauge and weather radar measurements. The resulting correlations differ for different links and reach values of $R^{2}=0.81$ for the link-gauge comparison and $R^{2}=0.85$ for the link-radar comparison.
\end{abstract}

\section{Introduction}

For the improved understanding of all aspects of the regional water cycle, knowledge of the spatio-temporal distribution of precipitation is of crucial importance. Improved and scientifically sound water availability information, however, still suffers from limited quality of available spatial rainfall products. This is particularly true in regions with complex orography and complex precipitation variability where the established precipitation measurement methods (rain gauges and radar) are prone to errors. The wind- and exposure-induced errors that rain gauges are affected by (Nešpor and Sevruk, 1999; Sevruk and Zahlavova, 1994) increase especially in complex terrain like the Alps. Weather radar measurements are in general subject to great uncertainties because of the error-prone relation between measured reflectivity and rain rate (Ulbrich and Lee, 1999) and the effect of the vertical profile of reflectivity (Joss and Pittini, 1991; Hazenberg et al., 2011). In mountainous regions, beam blockage and enhanced bright band interception introduce further errors (Andrieu et al., 1997).

A new possibility to gain additional information on precipitation is to use attenuation data from microwave links. This method makes use of the fact that rain drops considerably absorb and scatter electromagnetic radiation in the microwave region (wavelengths between $30 \mathrm{~cm}$ and $0.3 \mathrm{~cm}$, 
corresponding to frequencies between $1 \mathrm{GHz}$ and $100 \mathrm{GHz}$ ). The first theoretical description of this effect was given by Stratton (1930) and later proven by experiments of Mueller (1946). Both were focusing on the prediction of unwanted interference along a microwave communication link and thus treated precipitation as a source of disturbance. In the 1960s, weather radar researchers were the first who used the effect the other way around. They measured line integrated precipitation by using corner reflectors as fixed radar targets (Atlas, 1964). Among them were Atlas and Ulbrich (1977) who introduced the idea to use microwave point to point links instead of expensive radars. Since then, several experiments with purpose-built microwave links, mostly using two frequencies, were conducted to measure line integrated precipitation (Holt et al., 2003; Rahimi et al., 2004; Minda and Nakamura, 2005; Upton et al., 2005; Leijnse et al., 2007a) and its drop size distribution (DSD) (Rincon and Lang, 2002).

Messer et al. (2006) showed that it is possible to use attenuation data from existing commercial microwave link networks operated by mobile phone providers. Those networks exist wherever a mobile phone network exists. Thus, this technique can in general be employed even in areas with coarse gauge densities like mountainous regions or developing countries. The density of links of course varies, with more links in urban regions and a coarser network in rural areas. As a rough figure, a density of at least 0.3 links per $\mathrm{km}^{2}$ can be assumed for European countries. Reported approximate numbers are Germany 100000 links per $350000 \mathrm{~km}^{2}$ and Netherlands 12000 links per $35000 \mathrm{~km}^{2}$ (Leijnse et al., 2007b).

The potential of exploiting attenuation data from commercial microwave links networks has been studied both in theory and praxis to derive line integrated rain rates (Leijnse et al., 2007b; Schleiss and Berne, 2010; Townsend and Watson, 2011; Overeem et al., 2011), spatial rainfall fields (Zinevich et al., 2008) and humidity measurements (David et al., 2009). Leijnse et al. (2008) and Zinevich et al. (2010) also studied the impact of different error sources, like wet antenna attenuation and the variability of the drop size distribution.

In this study, we show results from data acquired at five links in the pre-alpine and alpine region around GarmischPartenkirchen in Southern Germany for the period July 2010 to October 2010. We use small data loggers mounted directly at the towers to record the received signal level (RSL) every minute with a power resolution $<0.05 \mathrm{~dB}$. To be able to continuously process the data, a new wet/dry classification algorithm that uses spectral time series analysis is introduced. Both its potential and limitations are shown. The rain rates produced by the algorithm are then compared with gaugeand radar-derived quantities.

\section{Physics of microwave attenuation by precipitation}

Attenuation of the transmitted power of an electromagnetic wave occurs when energy is scattered or absorbed by diffusers in the path of propagation. In the case of microwave radiation and liquid precipitation, those processes have to be described using the Mie solution to Maxwell's equations, because the diameter of the diffusers (i.e. the raindrop diameter $D \leq 5 \mathrm{~mm}$ ) and the wavelength used in microwave link systems $(\lambda \leq 3 \mathrm{~cm})$ are roughly in the same order of magnitude. Following the Mie solution, Olsen et al. (1978) showed that the relation between rain rate $R$ in $\mathrm{mm} \mathrm{h}^{-1}$ and attenuation $A$ in $\mathrm{dB} \mathrm{km}^{-1}$ can be approximated by the power law

$A=a R^{b}$.

The constants $a$ and $b$ primarily depend on the frequency of the propagating wave, but also on the shape of the drop size distribution (DSD) and the temperature. Problematic is the dependence on the DSD shape, because it is not only changing from rain event to rain event but even within the same rain shower on short scales in time and space. To determine its accuracy by remote sensing techniques is still an unsolved problem.

For different rainfall climatologies and DSDs, there are several sets of the values $a$ and $b$ available, both empirically and theoretically derived ones. They all have in common that $b$ is close or equal to one in the frequency range from $25 \mathrm{GHz}$ to $40 \mathrm{GHz}$. Hence, the power law in Eq. (1) is almost linear. This is an important fact, since any non-linearity leads to errors of the line integrated precipitation because of the inhomogeneous distribution of rain fall along the microwave link path (Leijnse et al., 2008).

We use the a- and b-values from the recommendation of the ITU (2003). For the values in between the listed ones, we perform a shape-preserving spline interpolation as shown in Fig. 1.

\section{Study region}

Our study region is the area between the cities Weilheim and Garmisch-Partenkirchen located in the southern part of Germany 40 to $90 \mathrm{~km}$ south of Munich. An overview of the region with the locations of all used microwave links, rain gauges and the weather radar is given in Fig. 2. It stretches from the upper Bavarian lowlands in the north at about $600 \mathrm{~m}$ a.s.l. to the high alpine area in the south with summits up to $3000 \mathrm{~m}$ a.s.l. (Zugspitze $2962 \mathrm{~m}$ ). Accordingly, the southern part of the study region is characterized by steep topography. Hence, strong gradients in temperature and mean rain rate exist on very short horizontal scales. In contrast to the lower parts of our study region with an annual precipitation of $1100 \mathrm{~mm}$ and a mean temperature of $8{ }^{\circ} \mathrm{C}$, the weather station on Zugspitze yields $2000 \mathrm{~mm}$ 


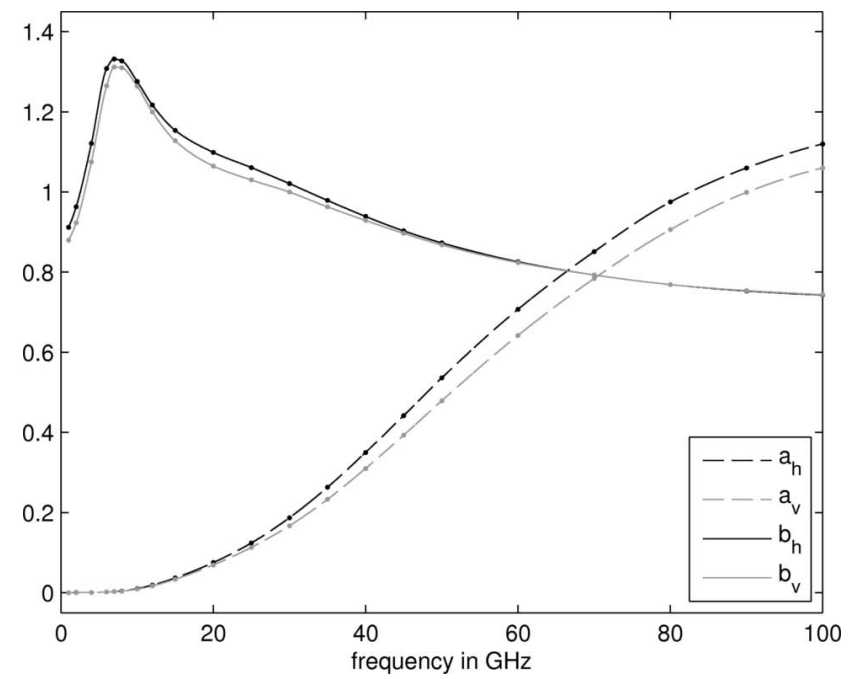

Fig. 1. Values of $a$ and $b$ for horizontal and vertical polarization used for the power law relation in Eq. (1). Dots are the values listed in the ITU recommendation. Lines are shape-preserving spline interpolations of the ITU data.

and $-4.7^{\circ} \mathrm{C}$. Furthermore, climatic conditions in the study region are characterized by strong seasonal and diurnal variations. The typical wind direction is southwest to northwest.

\section{Instrumentation}

\subsection{Microwave links}

We use data from five links from Ericsson $\mathrm{GmbH}$, which are part of a German mobile phone network. In contrast to other studies with commercial microwave links (Zinevich et al., 2008; Schleiss and Berne, 2010; Overeem et al., 2011), we do not receive any processed data from the network providers, but rather record the RSL directly at the towers from a monitoring output of the link systems. We use a data logger, described in more detail in Sect. 5, which sends the data to a database server via GSM. This restricts data acquisition to a smaller number of links, but gives the advantage of a high resolution of the RSL $(<0.05 \mathrm{~dB})$ and a selectable sampling rate.

Of the equipped links, two are located in the pre-alpine area around Mount Hoher Peißenberg where the German Meteorological Service (DWD) operates a meteorological observatory with the C-Band weather radar described in Sect. 4.3. The other three links are located in the valley around Garmisch-Partenkirchen. All links have a constant transmission power (in contrast to links that automatically change their transmission power to compensate for additional path attenuation). However, since they were not built as measurement devices, small changes (up to some tenths of $\mathrm{dB}$ ) due to temperature-dependent drifts of the electronics may be possible. Compared to the expected attenuation

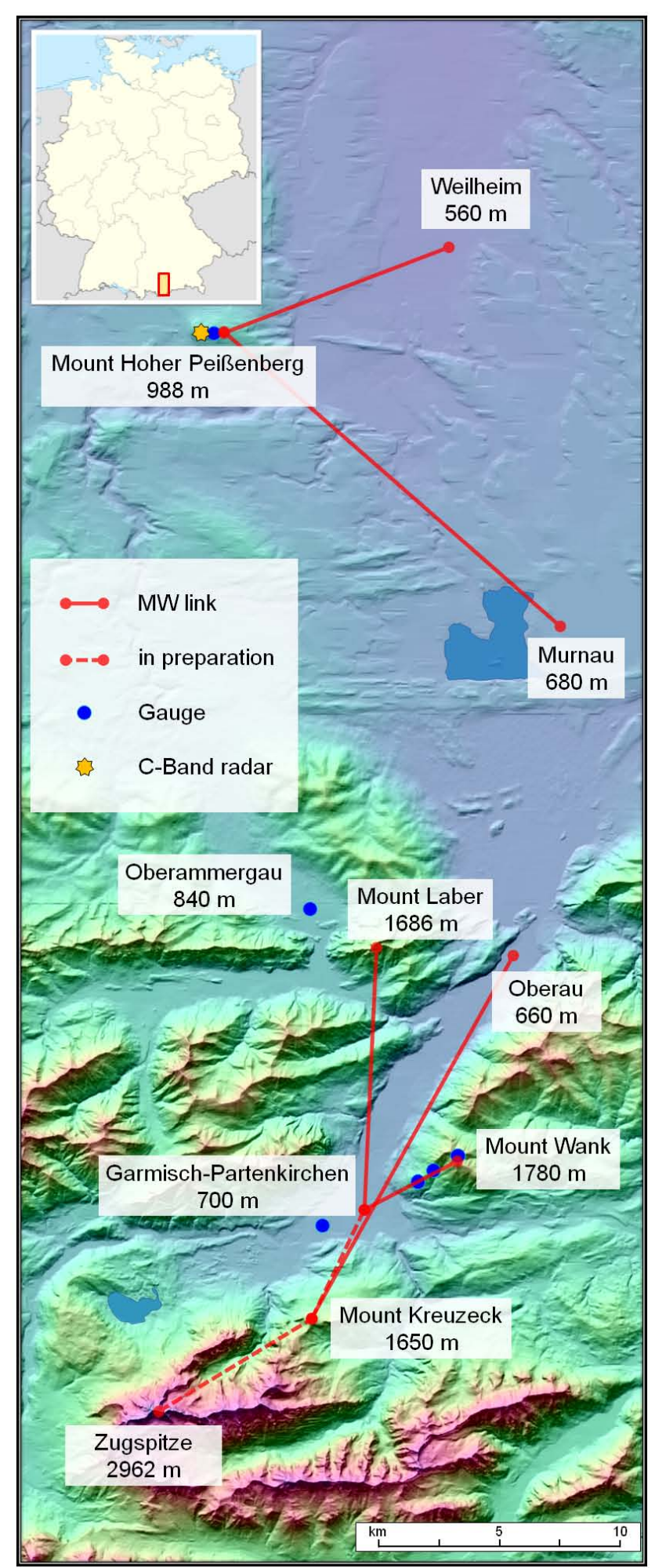

Fig. 2. Overview of the study region in Southern Germany showing the location of the DWD C-band radar, all microwave links and all rain gauges used in this study. 
along the link path, these changes are fairly small though. In this study, we thus assume a constant transmission power.

Details of link length, location, frequency, polarization and altitude difference are summarized in Table 1.

\subsection{Rain gauges}

For comparison with the link-derived rainfall rate, we use data from six rain gauges in the test area. Three gauges are operated by the DWD which provide hourly rain rate data with $0.1 \mathrm{~mm}$ resolution.

In addition to these, we operate three rain gauges at the slope beneath the steepest link connecting the center of Garmisch-Partenkirchen (700 ma.s.1.) and the summit of Mount Wank (1780 ma.s.l.) to better capture the inhomogeneity of precipitation caused by the orography. The gauges are tipping buckets with $0.2 \mathrm{~mm}$ resolution and are placed at $930 \mathrm{~m}, 1340 \mathrm{~m}$ and $1750 \mathrm{~m}$ a.s.l. Because all locations are on the steep forest-covered windward side of the mountain, the accuracy of the absolute values of rainfall amount is affected by large uncertainties. Qualitative information on the occurrence of rain events in general can nonetheless be deduced. A summary of all gauges can be found in Table 2 .

\subsection{Weather radar}

Radar data are obtained by the DWD C-band weather radar at Mount Hoher Peißenberg. It is not part of the operational radar network, which comprises 16 radar systems covering the whole area of Germany, but rather serves as a research testbed for innovations that could be introduced to the next generation of the operational network. Because of this, data are not always continuously available as soft- and hardware are being upgraded from time to time. Nevertheless, it is our preferred source of radar data because of its vicinity to the microwave links and to the Alps in general.

The radar covers a circular area with a radius of $256 \mathrm{~km}$ and generates a precipitation scan every five minutes. We use the reflectivity data of those five minute precipitation scans (the so-called DX product) with an angular resolution of $1^{\circ}$ and a range resolution of $1 \mathrm{~km}$. The DX product is already clutter-corrected by means of a statistical and a Doppler clutter filter. However, for the two links in the vicinity of the radar, ground clutter is already reduced by the elevated radar location on Mount Hoher Peißenberg approximately $300 \mathrm{~m}$ above the surrounding area. The radar beam elevation angle is $0.5^{\circ}$. Hence, the area around Garmisch-Partenkirchen is blocked by the mountains in between, making radar data unavailable for the three links in the southern part of our test region.

To derive rain rates from the radar reflectivity, we use the multi part Z-R-relation developed by the DWD within the RADOLAN project (Bartels et al., 2004). Details are given in Table 3. The resulting rain rates are then projected from polar coordinates to a $100 \times 100 \mathrm{~km}$ Cartesian grid with a grid size of $1 \times 1 \mathrm{~km}$.

\section{Data acquisition and data management}

\subsection{Data logger}

To acquire RSL data from the microwave links, data loggers are connected to the RSL monitoring voltage output at the links. We use a Cinterion TC65i which combines a GSM module, two ADC (analog-to-digital converter) channels and a Java virtual machine to run our custom logging program. The module's ADC input is connected to the RSL monitoring voltage output of the link. If a second link is available at the same location, its RSL output can be connected to the second ADC, which will help save costs when installing loggers at nodes where usually several links are located.

The RSL monitoring voltage is sampled every three seconds and stored as a minute average. Via the GSM module, the recorded data are then transferred to the FTP port of the project server. Since the minimal java virtual machine installed ex factory does not implement FTP, the free FTP library Ftp2Me (László, 2011) is used. With a conversion factor distinct for each link system, the recorded voltage can then be converted to RSL in the next processing step. The conversion factors are provided by Ericsson GmbH. To assure good data consistency, the logger requests the current time via time protocol from the Physikalisch-Technische Bundesanstalt (PTB) in Germany to update its systems time used to timestamp the data. Each logger also has a unique International Mobile Station Equipment Identity (IMEI) number which is used to organize the raw data storage at the server so that distinguishing data from different loggers is straightforward. The cryptic IMEI is then resolved to the real microwave link name in the database.

If RSL data are not directly available from the backhaul network providers or if higher resolution data are required for research, the developed data logger can offer a simple and cheap alternative. Given that permission from the provider is obtained, installation is possible wherever the used microwave link hardware provides an analog RSL voltage monitoring output.

\subsection{Database and data access}

To ease analysis, processing and storage organization of the daily increasing amount of RSL records, a database system is used. The framework consists of a MySQL backbone, containing the tables for all data, and python scripts for parsing and exporting data to and from the database. Besides RSL data, it also contains all important information on the specific microwave links (locations, frequency, polarization, etc.), rain gauge data and additional meteorological data from our institute's met station on the summit of Mount Wank. It is easily expandable for new data sources. Export for automatic 
Table 1. Table of all links used in this study.

\begin{tabular}{|c|c|c|c|c|c|c|}
\hline Name & From & To & Length & $\begin{array}{c}\text { Altitude } \\
\text { difference }\end{array}$ & Frequency & Polarization \\
\hline hop2-murn1 & Mount Hoher Peißenberg & Murnau & $17.4 \mathrm{~km}$ & $300 \mathrm{~m}$ & $15.0 \mathrm{GHz}$ & vertical \\
\hline hop2-wh0 & Mount Hoher Peißenberg & Weilheim & $10.2 \mathrm{~km}$ & $420 \mathrm{~m}$ & $18.7 \mathrm{GHz}$ & vertical \\
\hline gap0-gap4 & Garmisch-Partenkirchen & Mount Wank & $4.0 \mathrm{~km}$ & $1050 \mathrm{~m}$ & $18.7 \mathrm{GHz}$ & horizontal \\
\hline gap3-oau4 & Mount Kreuzeck & Oberau & $17.1 \mathrm{~km}$ & $950 \mathrm{~m}$ & $15.0 \mathrm{GHz}$ & vertical \\
\hline gap0-oagau1 & Garmisch-Partenkirchen & Mount Laber & $10.4 \mathrm{~km}$ & $940 \mathrm{~m}$ & $23.0 \mathrm{GHz}$ & vertical \\
\hline
\end{tabular}

Table 2. Table of rain gauges used in this study.

\begin{tabular}{llcc}
\hline Name & Location & Altitude & Accuracy \\
\hline gap & Garmisch-Partenkirchen & $720 \mathrm{~m}$ & $0.1 \mathrm{~mm} \mathrm{~h}^{-1}$ \\
oagau & Oberammergau & $840 \mathrm{~m}$ & $0.1 \mathrm{~mm} \mathrm{~h}^{-1}$ \\
hop & Hoher Peißenberg & $960 \mathrm{~m}$ & $0.1 \mathrm{~mm} \mathrm{~h}^{-1}$ \\
wank900 & Mount Wank & $930 \mathrm{~m}$ & $0.2 \mathrm{~mm} \mathrm{~h}^{-1}$ \\
wank1300 & Mount Wank & $1340 \mathrm{~m}$ & $0.2 \mathrm{~mm} \mathrm{~h}^{-1}$ \\
wank1750 & Mount Wank & $1750 \mathrm{~m}$ & $0.2 \mathrm{~mm} \mathrm{~h}^{-1}$ \\
\hline
\end{tabular}

processing and research work can be done via a command line tool to CSV (comma-separated values) files or binary matlab structures. Raw data are not yet freely available, but a web interface for visualization is already online (Gmeiner, 2011).

\section{Data preprocessing: wet/dry classification}

\subsection{Background}

As shown in Sect. 2, the attenuation of microwave radiation strongly depends on the amount of precipitation along its path of propagation. Hydrometeors are however not the only source of disturbance. All other atmospheric parameters like gas concentrations, pressure, humidity, temperature and even aerosols (Liebe, 1989) or dust particles (Ho et al., 2004) can cause signal impairment. Small changes of the transmission power due to drifts of the link electronics may also alter the RSL. However, compared with the impact of precipitation, these effects are minor. But even during clear sky conditions, the RSL level is always fluctuating, because the atmospheric conditions are constantly changing. For special layering of the atmosphere, so-called ducting, where gradients of the refractive index cause the direction of wave propagation to bend, losses of several $\mathrm{dB}$ are possible (Valtr et al., 2011). Thus, to derive meaningful precipitation information from microwave link data, the fluctuations of the RSL have to be distinguished from those caused by precipitation and those caused by other effects. As there is usually no reliable information on the atmospheric conditions along the links available, discounting their impairment on the signal is not
Table 3. Table containing the values of $a$ and $b$ used for the conversion of radar reflectivity $Z$ to rain rate $R$ with $R=a Z^{b}$ according to findings of the RADOLAN project. Overestimation of convective precipitation and underestimation of stratiform precipitation shall be avoided by distinguishing precipitation types from the reflectivity values (in $\mathrm{dBZ}$ ) and a shower index for each pixel. The later is the mean value of the absolute differences in reflectivity of the neighbouring pixels (Bartels et al., 2004).

\begin{tabular}{lccccc}
\hline \multirow{2}{*}{$\begin{array}{l}\mathrm{yBZ} \\
\text { shower index }\end{array}$} & $<3.5$ & $3.5-7.5$ & $>7.5$ & & \\
\cline { 2 - 5 } & 125 & 200 & 320 & 200 & 74 \\
\hline$a$ & 1.4 & 1.6 & 1.4 & 1.6 & 1.9 \\
\hline
\end{tabular}

feasible. In order to still derive meaningful rain rates from microwave link data, two directions can be taken.

First, the differential polarization signal from a dual polarization-link cancels out the unwanted fluctuations (Ruf et al., 1996). This is because the differential signal is only affected by the unequal raindrop diameters in the horizontal and vertical direction depending on the drop sizes, which in turn depends on the rain rate.

The second way is to determine in which periods rain events occurred (wet period) and which were dry (dry periods). The attenuation during a rain event could then be calculated from a baseline, which is derived from the dry period before it, assuming that the baseline does not significantly change during the rain event. This was first shown by Rahimi et al. (2003) who analysed the correlation between RSL time series for different frequencies recorded with purpose built dual-frequency links. Wet events could be distinguished from dry ones by significantly higher correlation values. The same approach was taken by Goldshtein et al. (2009) using the correlation between bidirectional signals of commercial links. An extension to this method was presented by Rayitsfeld et al. (2012) using a hidden Markov model. Overeem et al. (2011) also analysed correlation between different links to detect wet periods. They compared RSL levels of several links (not farther than $10 \mathrm{~km}$ from each other) from a dense network of microwave links in an urban area.

In commercial microwave link networks, usually only one polarization and one frequency are available along a certain 
link path. Density of the network also varies considerably between rural and urban areas. Hence, the above-mentioned methods are not always applicable. Nevertheless, a determination of wet and dry periods is possible using time series analysis tools. Schleiss and Berne (2010) showed that a windowed standard deviation sliding along a RSL record from commercial links accomplished this task quite robustly. Applying this method to our specific data (i.e. specific data resolution, link topography and alpine/pre-alpine terrain), we encountered some limitations though. Distinguishing between light rain events and dry fluctuations was not always successful. Thus, we developed a new analysis tool, using short-time Fourier transform (STFT), which is a sliding windowed fast Fourier transform (FFT).

\subsection{Algorithm}

The problem to distinguish wet and dry periods in the RSL data records can be viewed as a problem of pattern recognition in time series. A human observer, who has experience in comparing RSL data with rain gauge records, can very often easily detect even weak rain events by looking at the course of the RSL time series. For larger data sets, this is of course not feasible and scientifically not satisfying. Thus, the main task is to find features defining "the look" of a rain event that are easily extractable from the time series by means of a computer algorithm.

We approach this task by analysing spectra of short snippets of the RSL time series $R_{i}$ with $i \in\{1, \ldots, N\}, N$ being the length of the time series. For each time step $t$, we take short section of the RSL data:

$\boldsymbol{R}(t)=\left\{R_{k} \mid k \in\{t-L, \ldots, t+L\}\right\}$

with length $2 L$ (a length of 256 points was found to perform best and is used throughout this paper), windowed by a Hamming window $\omega$, from which we calculate the Fourier transform:

$\mathcal{F}(f, t)=\operatorname{FFT}(\omega \boldsymbol{R}(t))$

via FFT. As we are only interested in the spectrum of the amplitudes, we use the power spectral density

$P(f, t)=\frac{2|\mathcal{F}(f, t)|^{2}}{F_{\mathrm{S}} \sum_{0}^{L} \omega^{2}}$

for further analysis. The normalisation factors used are the sampling rate $F_{\mathrm{s}}$ and the sum over all Hamming window weights. The received spectrum is just a different representation of the short time series section around $t$, only in the frequency domain. Effects that occur at a certain frequency or in a certain frequency range are thus more easily observable. Figure 3 shows example spectra for three points in time of a RSL record with different atmospheric conditions: a rain event, a dry period and a dry period that causes strong signal fluctuations.

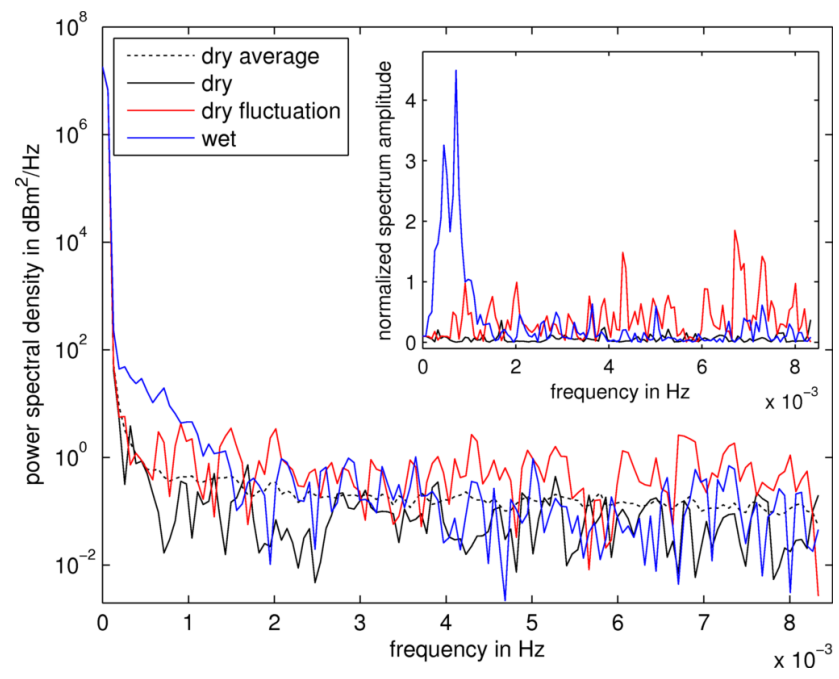

Fig. 3. Typical spectra for 256 min snippet (with a Hamming window) from a RSL time series for different atmospheric conditions. The inset shows the spectra normalised with the average dry spectrum by division. Deviation from the mean dry spectrum is largest for the low frequency part of the wet-spectrum. Note that for the $d r y$ fluctuation-spectrum the observable deviation is highest in the high frequency part.

The raw spectra all exhibit a similar $1 / f$-like shape with increasing amplitudes towards low frequencies. To ease the analysis of the amplitude deviations during rainy periods compared to dry periods, a normalisation of the spectra has to be applied. Using a general spectrum (e.g. $1 / f^{\alpha}$ with $\alpha \in$ $[0.5,1])$ for the normalisation of all links did not yield satisfying results. This is due to the fact that the link spectra deviate from $1 / f^{\alpha}$ in the low frequency regime. The deviations also differ for each link.

Thus, for each point in time $t$, the normalised spectrum

$P_{\text {norm }}(f, t)=\frac{P(f, t)}{P_{\text {mean dry }}(f)}$

is calculated by division through a mean dry spectrum

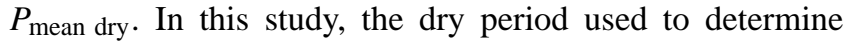
$P_{\text {mean dry }}$ was chosen by visual inspection of the RSL time series. The duration of the averaging period was approximately $48 \mathrm{~h}$ for each link. However, since this step has to be performed only once for each link, the dry period could be chosen by selecting a time of stable dry weather from reanalysis or gauge data. Using this approach, a determination of $P_{\text {mean dry }}$ would also be feasible for a larger number of links.

The inset in Fig. 3 shows the three spectra for the three different atmospheric conditions in normalised form. Besides the obvious strong deviation at low frequencies for the wet period, the dry period with strong fluctuations also shows considerable differences from the dry mean. Contrary to the wet period, its deviation spreads over the whole frequency range with the highest amplitudes towards high frequencies. That is, not only can the wet periods be identified by the 
strong deviation at low frequencies, but they can also be distinguished from dry periods by the uneven distribution of the deviations. Hence, we look at the difference

$P_{\text {sum diff }}(t)=P_{\text {sum low }}(t)-P_{\text {sum high }}(t)$

of the sums of the normalised low and high frequency amplitudes

$$
\begin{aligned}
P_{\text {sum low }}(t) & =\sum_{f \leq f_{\text {divide }}} \frac{P_{\text {norm }}(f, t)}{N_{\text {low }}} \\
P_{\text {sum high }}(t) & =\sum_{f>f_{\text {divide }}} \frac{P_{\text {norm }}(f, t)}{N_{\text {high }}}
\end{aligned}
$$

with $f_{\text {divide }}$ defining the frequency at which the spectrum is divided and $N_{\text {low }}, N_{\text {high }}$ being the number of frequencies used in each sum.

If the difference $P_{\text {sum diff }}$ exceeds a certain threshold $\sigma$, we mark the period as wet. Hence, for each point in time $t$, we define the decision rule:

$t=\left\{\begin{array}{l}\text { wet if } P_{\text {sum diff }}(t)>\sigma \\ \text { dry if } P_{\text {sum diff }}(t) \leq \sigma .\end{array}\right.$

During wet periods, the baseline $R_{\text {base }}$ of the RSL is kept constant at the level of the last value $t_{\text {lastdry }}$ of the last dry period. For the dry period, the baseline always follows the RSL level. That is

$R_{\text {base }}(t)= \begin{cases}R\left(t_{\text {lastdry }}\right) & \text { if wet } \\ R(t) & \text { if dry }\end{cases}$

The attenuation is then

$A(t)=R_{\text {base }}(t)-R(t)$

which is always zero for the dry periods. If the attenuation (and thus the rain rate) becomes negative, the rain rate is set to zero. This sometimes happens at the end of a rain event when the baseline was set too low at the beginning.

\subsection{Example}

For the following exemplary application of the algorithm presented in the last section, the threshold $\sigma=2.5$ and the spectrum division frequency $f_{\text {divide }}=4.3 \times 10^{-3} \mathrm{~Hz}$ have been chosen by hand. Section 6.4 will deal with the optimization of these two parameters to get optimal wet and dry detection performance.

The example of the application of the wet/dry classification algorithm is shown in Fig. 4. It is applied to a 18-day time series of RSL data recorded in summer 2010 at the link gap0-oagaul from Garmisch-Partenkirchen to Mount Laber near the city of Oberammergau. The topmost plot (Fig. 4a) shows the minute resolution RSL time series recorded by our data logger. Within the 18 days, several rain showers passed the link. The slight attenuation events around the 19 and
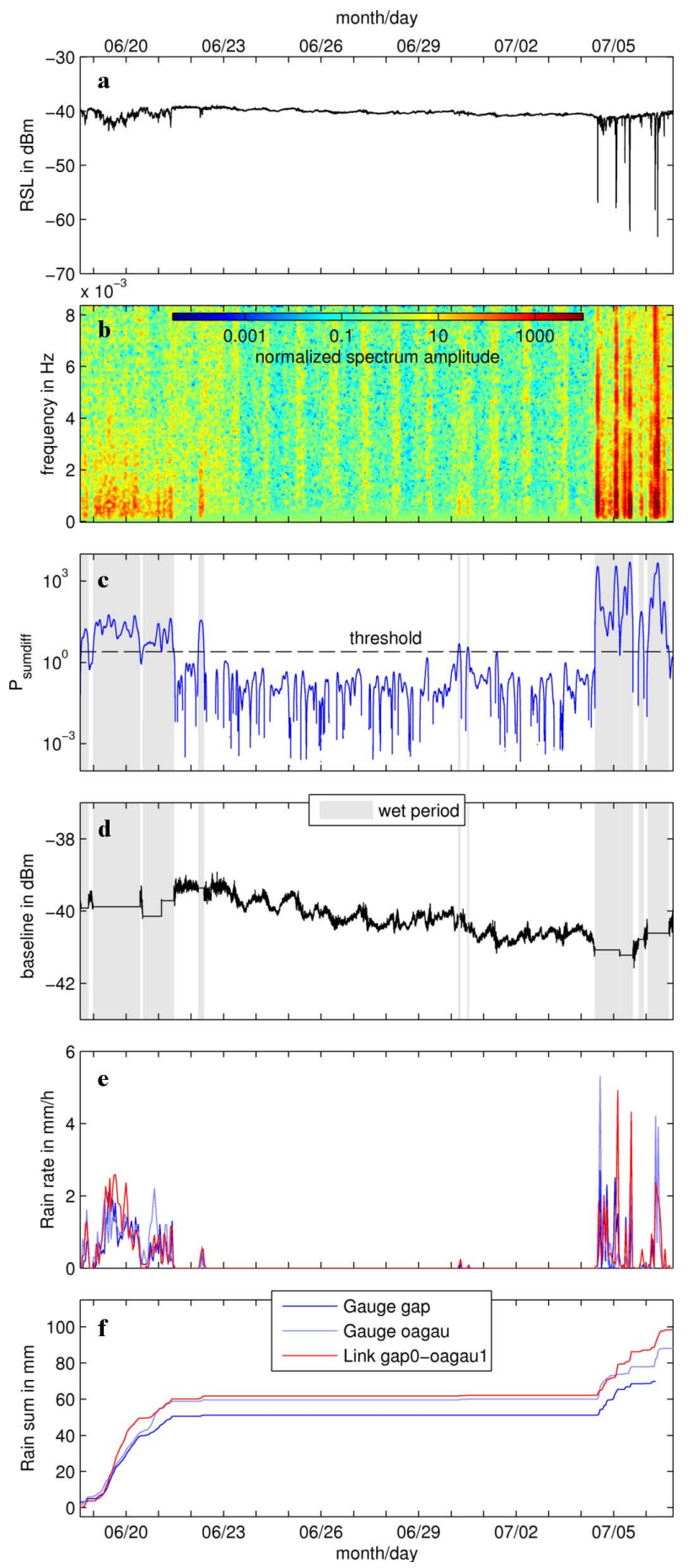

Fig. 4. Application of the proposed wet/dry classification algorithm to a 18-day RSL time series in summer 2010 from the link gap0oagaul. The plots from top to bottom show (a) the RSL time series, (b) its spectrogram, (c) the difference of the spectrum amplitude sums $P_{\text {sumdiff }}$ (see text for explanation), (d) the derived baseline for the RSL time series and (e) the calculated rain rates plus (f) the accumulated sum, both compared to two nearby rain gauges. 
20 June indicate a long lasting stratiform rain event. On the 22 and 30, three weak and short events occurred. The last days of the time series around the 4 and 5 July are dominated by sharp attenuation events, which can be assumed to stem from more convective showers.

In Fig. 4b, a spectrogram of this time series is shown that comprises the normalised spectra $P_{\text {norm }}(t)$ for each minute, with the frequency along the $y$-axis and the amplitude colour coded. A window length of 256 points was used. The uneven distribution of the normalised amplitudes during rain events (which was already shown in Fig. 3) is also visible in this representation of the time series. During the dry period from the 23 to the 29 June, a daily periodicity is revealed with stronger fluctuations (higher amplitudes) in the morning hours.

To visualize the decision of whether a period is wet or dry, $P_{\text {sumdiff }}$ and the threshold $\sigma$ are plotted in Fig. 4c. Following the decision rule in Eq. (9), a shaded area is added to indicate a wet period where $P_{\text {sumdiff }}>\sigma=2.5$. The baseline, shown in the Fig. 4d, is then set according to Eq. (10). With the magnified $y$-axis compared to the topmost plot, the fluctuations during dry periods are now clearly visible.

With the baseline set, it is now straightforward to calculate the rain rate with the power law from Eq. (1) and the a- and $b$-values taken from the interpolation of the ITU recommendations. Figure $4 \mathrm{e}-\mathrm{f}$ comprise the calculated hourly rain rates and accumulated sum of rain, respectively. For comparison, data from the two nearest DWD rain gauges are shown. Reasonable agreement can be observed between all three precipitation observations. Deviations are of course likely because the gauges are several kilometres away from the link and thus they do not necessarily collect the same amount of rain.

\subsection{Adjustment and performance for different links}

For the example shown in Fig. 4, the threshold $\sigma$ and the frequency $f_{\text {divide }}$, at which the spectrum is divided, were chosen by hand to best fit the event detection by the rain gauge. However, this is not feasible for a larger number of links and a longer time series. To determine the best values for $\sigma$ and $f_{\text {divide }}$ for each of the five links, we analysed our algorithm's performance for a wide range of values over the period July 2010 to October 2010. Measures of the performance are the error rates of wet and dry detection which are based on the number of wet and dry hours for link and gauge measurements. Important to note is that the hourly classification of the link data is based on the mean hourly rain rate. Only if it is larger than zero, the hour is classified as wet. Hence, it is possible that an hour containing minutes that were classified as wet is not counted as wet in this analysis, if it did only contain negative minutely rain rates which were set to zero during processing. Negative rain rates (or negative attenuation) occur if the RSL baseline is set too low, which may happen for values of $\sigma$ far below the optimum. In this case, the baseline will be set at an inappropriate moment. It may then remain unchanged for a long time, because, for very low values of $\sigma$, most of the periods are classified as wet, since $P_{\text {sumdiff }}$ easily exceeds $\sigma$. For this reason, the number of hours classified as wet here does not steadily decrease with increasing $\sigma$, although the number of minutes classified as wet by the wet/dry classification algorithm does.

Using the numbers of hours $N_{\text {link\&gauge=wet }}$ and $N_{\text {link\&gauge }=\text { dry }}$, where both link and gauge are classified as wet or dry respectively and the number of hours $N_{\text {gauge=wet }}$ and $N_{\text {gauge }=\text { dry }}$, where the gauge indicates a wet or dry period, respectively, we define the error rates as

$\mathcal{E}_{\text {wet }}=1-\frac{N_{\text {link\&gauge }=\text { wet }}}{N_{\text {gauge }=\text { wet }}}$
$\mathcal{E}_{\text {dry }}=1-\frac{N_{\text {link\&gauge }=\text { dry }}}{N_{\text {gauge }=\text { dry }}}$

which form the weighted mean error rate

$\mathcal{E}_{w \text { mean }}=w \mathcal{E}_{\text {wet }}+(1-w) \mathcal{E}_{\text {dry }}$

with the weighting factor $w$. We chose $w=0.6$ to emphasise the error of wet detection. This is motivated by the fact that a misclassification of a dry period as wet is less severe, since, if the gauge is regarded as truth, it is not raining in this period. Hence, the attenuation (and thus the rain rate derived from the link) is expected to be low (Rahimi et al., 2003). The dry error of course still has to be taken into account due to the possibility of large fluctuations in absence of rain, which is exactly the reason why a wet/dry classification is necessary.

Besides $\sigma$ and $f_{\text {divide, }}$, the window length, which should be a power of 2 for fast computation of the Fourier transform, is another crucial parameter for the algorithm's performance. We found that 256 points (with our minute-averaged data, i.e. $256 \mathrm{~min}$ ) performed best. Shorter windows yielded more problems with detecting long lasting, almost constant rain events, for the short window does not see the long-term fluctuation. Longer windows in contrast had drawbacks in detecting small and short events because their contribution to the Fourier spectra is blurred out.

The results of the performance analysis for a window length of 256, with threshold values $-6 \leq \sigma \leq 6$ and frequency division values $0 \mathrm{~Hz} \leq f_{\text {divide }} \leq 8.3 \times 10^{-3} \mathrm{~Hz}$, are given in Fig. 5. All five links exhibit more or less the same behaviour. Apart from the non-continuously rising or falling region at low $\sigma$ values, a larger $\sigma$ yields a lower dry detection error rate (because more and more points are classified as dry since $P_{\text {sumdiff }}$ is smaller than $\sigma$ more often) and a higher wet detection error rate (because fewer and fewer points are classified as wet). Above a certain threshold value $\sigma \approx 0$, the dry detection error rate of all links rapidly decreases, converging to zero for increasing $\sigma$. The increase of the wet detection error rates also starts at $\sigma \approx 0$. Except for hop2-murnl (see Fig. 5-b5), this increase is small compared to the decrease of the dry detection rate. The cause for the peculiar behaviour of hop2-murnl is not yet clear.

Figure 5-b1 to 5-b5 also reveal the influence of the value of $f_{\text {divide }}$ on the error rate. With lower $f_{\text {divide }}$, the increase 

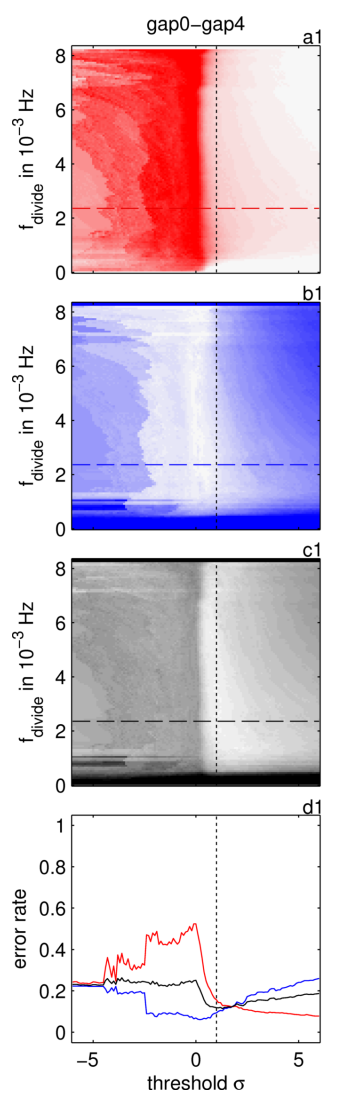
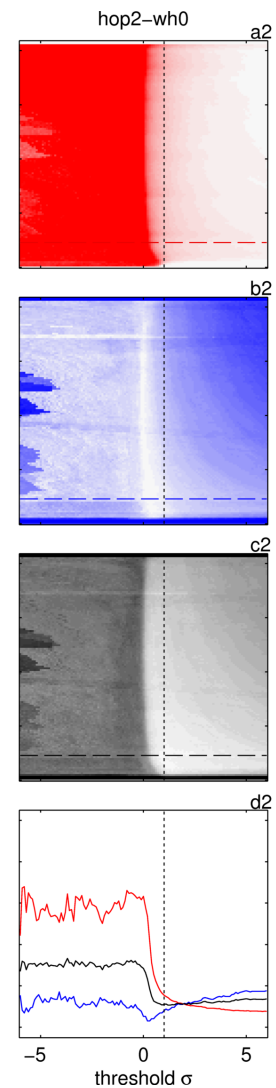
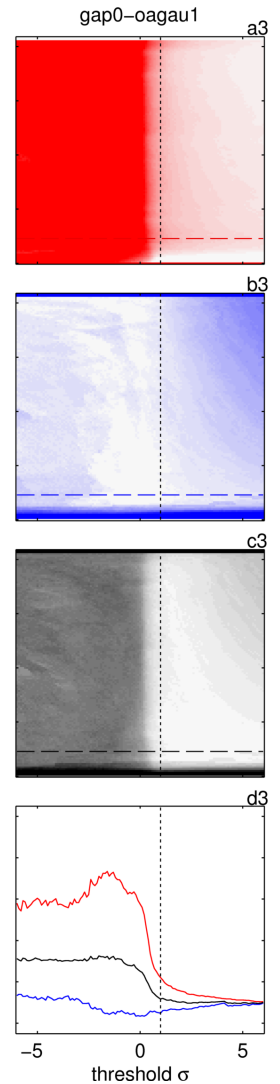
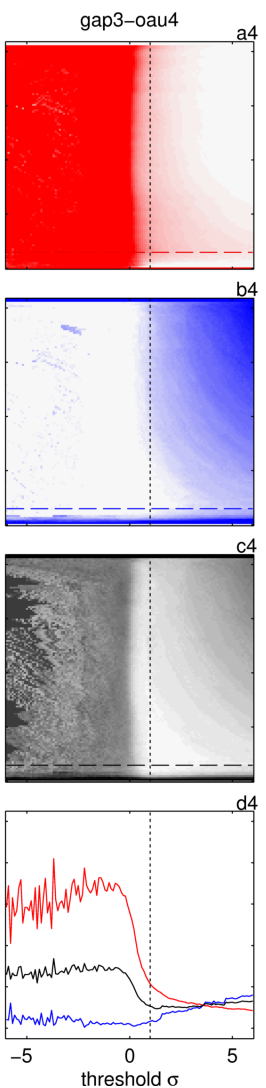
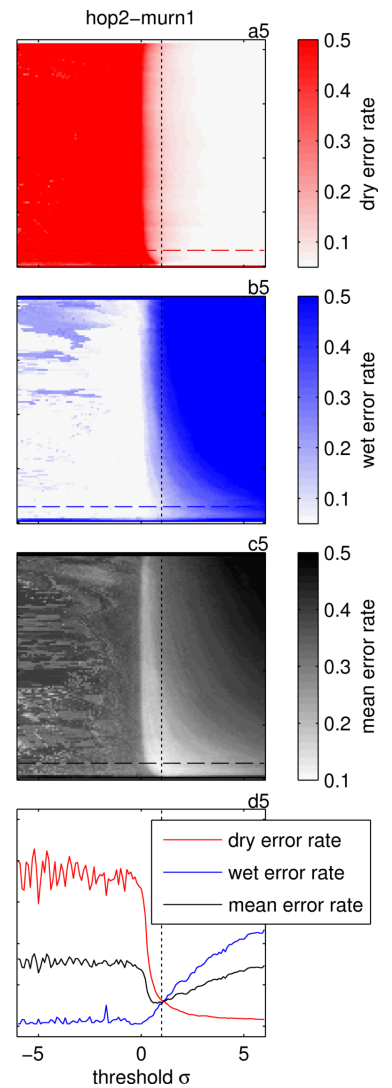

Fig. 5. Wet, dry and weighted mean detection error rates for the five links depending on the threshold $\sigma$ and the frequency of spectrum division $f_{\text {divide. }}$. A window length of 256 was used. The bottommost plots (d1 to d5) show the evolution of the error rates for different $\sigma$ at a certain $f_{\text {divide }}$ indicated by the dashed lines in plots a,b and c. The chosen values for $f_{\text {divide }}$ are proportional to the reciprocal of the link length (detail see text). The links are sorted from left to right with increasing length.

of $\mathcal{E}_{\text {wet }}$ towards higher threshold values $\sigma$ is slowed down, resulting in a wider range of good $\sigma$ values. There is a lower boundary for optimal $f_{\text {divide }}$ values though. If $f_{\text {divide }}$ is set too low, the effect of rain events on the spectrum amplitudes (the increased amplitudes in the low frequency regime) is not contained in $P_{\text {sumlow }}$ anymore. Thus, $P_{\text {sumdiff }}$ stays small and does not exceed $\sigma$. Hence, less or no periods are classified as wet. This lower boundary of $f_{\text {divide }}$ is dependent on the link length (note that the links in Fig. 5 are sorted by link length, increasing from left to right). The longer the link, the more averaging occurs. Thus, the time scales on which changes in the RSL happen become longer (Leijnse et al., 2008). That is, the frequencies at which rain events impact the RSL time series should decrease with increasing link length.

All the described effects on the dry and wet detection error rates determine the optimal values of $\sigma$ and $f_{\text {divide }}$ for the mean error rates $\mathcal{E}_{\text {mean }}$ shown in Fig. 5-c1 to c5. The minimum of $\mathcal{E}_{\text {mean }}$ lies where $\mathcal{E}_{\text {dry }}$ just declined and $\mathcal{E}_{\text {wet }}$ starts to rise $(\sigma \approx 1)$ with a bias towards low $f_{\text {divide }}$ depending somehow on the link length. The optimal values of $\sigma$ and $f_{\text {divide }}$ for minimal $\mathcal{E}_{\text {mean }}$ are listed in Table 4.
Following the idea of a dependence of $f_{\text {divide }}$ on the link length $l$, a suitable value for $f_{\text {divide }}$ can be estimated. We assume a maximum propagation speed of near surface rain fields of $v=10 \mathrm{~m} \mathrm{~s}^{-1}$ and a propagation along the link direction. The time needed for travelling along the link length is then $t=l / v$. This can be thought of as a convolution of the rain field and a rectangular function (the line integral along the link) of length $t$. The resulting spectrum is then the spectrum of the rain field multiplied with a sinc function (Fourier transform of a rectangular function), which has its first zero at $f_{0}=1 / t$. That is, whatever the shape and hence the spectrum of the rain field is, most of the effect on the RSL spectrum should be contained below $f_{0}=1 / t=v / l=$ $1 / l \times 10^{-2} \mathrm{~Hz}$ with $l$ in kilometres. This of course will in reality depend on the prevailing wind direction, which changes the effective length of the link seen by the passing rain field. Nevertheless, as can be observed in Fig. 5 (the dashed lines indicate $f_{\text {divide }}=1 / l \times 10^{-2} \mathrm{~Hz}$ ) and seen from the resulting error rates in Table 4, the performance with a constant $\sigma=1$ (indicated by the dotted lines in Fig. 5) is very close to the absolute optimum. 
Table 4. Resulting mean error rate $\mathcal{E}_{\text {mean }}$ of the wet dry classification algorithm with the corresponding optimum values (also depicted in Fig. 5) of $\sigma$ and $f_{\text {divide. }}$. Also listed are the near optimum values for which $f_{\text {divide }}$ follows the reciprocal of the link length (see text for details) and $\sigma=1$. For comparison with the link length, the reciprocal of $f_{\text {divide }}$ is given. The correlation coefficients $R^{2}$ stem from the comparison of the link-derived rain rates with rain gauge data in section 7 using the near optimum values. A window length of 256 min was used in the underlying analysis.

\begin{tabular}{|c|c|c|c|c|c|c|c|c|c|}
\hline \multirow{2}{*}{ Link name } & \multirow{2}{*}{$\begin{array}{l}\text { Length } \\
\text { in } \mathrm{km}\end{array}$} & \multicolumn{3}{|c|}{ Optimum } & \multicolumn{5}{|c|}{ Near optimum } \\
\hline & & $f_{\text {divide }}$ in $\mathrm{Hz}$ & $\sigma$ & $\mathcal{E}_{\text {wmean }}$ & $f_{\text {divide }}$ in $\mathrm{Hz}$ & $f_{\text {divide }}^{-1}$ in seconds & $\sigma$ & $\mathcal{E}_{\text {wmean }}$ & $R^{2}$ \\
\hline gap0-gap4 & 4.0 & $2.60 \times 10^{-3}$ & 1.1 & 0.110 & $2.40 \times 10^{-3}$ & $0.42 \times 10^{3}$ & 1.0 & 0.119 & 0.61 \\
\hline hop2-wh0 & 10.2 & $0.85 \times 10^{-3}$ & 1.0 & 0.102 & $0.92 \times 10^{-3}$ & $1.09 \times 10^{3}$ & 1.0 & 0.110 & 0.81 \\
\hline gap0-oagau1 & 10.4 & $0.72 \times 10^{-3}$ & 3.9 & 0.090 & $0.92 \times 10^{-3}$ & $1.09 \times 10^{3}$ & 1.0 & 0.117 & 0.75 \\
\hline gap3-oau4 & 17.1 & $0.79 \times 10^{-3}$ & 1.9 & 0.088 & $0.59 \times 10^{-3}$ & $1.67 \times 10^{3}$ & 1.0 & 0.106 & 0.74 \\
\hline hop2-murn1 & 17.4 & $0.39 \times 10^{-3}$ & 1.0 & 0.111 & $0.59 \times 10^{-3}$ & $1.67 \times 10^{3}$ & 1.0 & 0.114 & 0.61 \\
\hline
\end{tabular}

To strengthen these findings, further research will be needed in particular with a larger number of links at an ideally wide range of lengths also taking into consideration link orientation and wind directions, which can be highly variable in our alpine region. Nevertheless, the results shown here give a strong indication that this method could be applied without calibration, setting $\sigma=1$ and $f_{\text {divide }} \approx$ $1 / l \times 10^{-2} \mathrm{~Hz}$. For the derivation of the rain rates from the RSL in Sect. 7, these values will be used.

The same analysis as shown in Fig. 5 was also conducted with radar data as reference for the performance of the wet/dry classification algorithm. Using radar rainfall as criteria for wet/dry classification is not straightforward though. Radar rain rates are derived from radar reflectivity (as described in Sect. 4.3) which can result in very small rain rates for the smallest reflectivity values just above the radar system's detection limit. These small rain rates do not necessarily correspond to real rainfall. Hence, usually a threshold of $0.1 \mathrm{~mm} \mathrm{~h}^{-1}$ is introduced and lower rain rates are set to zero. However, our radar data show artefacts (identified by careful analysis of the temporal evolution of the spatial radar reflectivity) resulting in rain rates of up to $0.3 \mathrm{~mm} \mathrm{~h}^{-1}$. For the wet/dry classification performance analysis, we thus had to find a compromise between reducing the artefacts (false wet periods) and accidentally neglecting small real rain events. We used a threshold of $0.1 \mathrm{~mm} \mathrm{~h}^{-1}$ for the $5 \mathrm{~min}$ radar data and classified an hour as wet if the hourly radar rain rate averaged along the corresponding link was larger than $0.2 \mathrm{~mm} \mathrm{~h}^{-1}$. The optimal values for $\sigma$ and $f_{\text {divide yielded by }}$ this analysis were close to the ones found using gauge data, resulting in minimum mean error rates of $\mathcal{E}_{\text {mean }}=0.120$ and $\mathcal{E}_{\text {mean }}=0.098$ for the links hop2-murnl and hop2-wh0. As mentioned in Sect. 4.3, radar data were not available for the three links around Garmisch-Partenkirchen because of beam blockage due to the mountains.

Because of the higher spatial representativeness of the radar compared to the rain gauge (explained in Sect. 6.5), we expected a better performance using radar data. For the link hop2-who, this proved to be true, although with a marginal improvement from $\mathcal{E}_{\text {mean }}=0.102$ to $\mathcal{E}_{\text {mean }}=0.098$. For the link hop2-murn 1, however, performance decreased slightly from $\mathcal{E}_{\text {mean }}=0.111$ to $\mathcal{E}_{\text {mean }}=0.120$. Most likely the mentioned artefacts and the errors introduced by neglecting small rain rates lead to this result.

\subsection{Limitations}

As can be seen from the error rates in Fig. 5 and Table 4, there still remains an amount of misclassifications of wet and dry periods. Some are due to the inability of the algorithm itself, others to the more general problem of precipitation ground truthing.

In our case, the rain gauge locations and the farthest point of some links are separated by more than $10 \mathrm{~km}$ and up to $1000 \mathrm{~m}$ of altitude difference. That is, the rain gauge indicating a dry period does not necessarily mean that there was no rain along the link at all. As mentioned in Sect. 6.4, the available radar data, which in principle could serve to overcome this problem, contain small rain rate artefacts and are thus not usable for this task.

Figure 6 gives an example of a situation like this where the gauge misses a rain event. The RSL data show three distinct attenuation events: at 06:00, 11:30 and 13:00 UTC. Judging by the course of the RSL, all three stem from precipitation. The rain gauge, however, seems to miss the second event and parts of the third one. Hence, a dry detection error is counted where the algorithm in fact was correct. Unfortunately, a comparison with radar data, which would offer an improved more localised event detection, is not possible for the three links around Garmisch-Partenkirchen because no radar data are available for the test period in summer 2010. The cause for this was a new scan strategy that set the elevation angle of the radar lower for the precipitation scan. Hence, the beam is blocked by the mountain range north of Garmisch-Partenkirchen.

Besides the problem with the spatial representativeness of rain gauges, Fig. 6 also shows a detection limitation of the algorithm itself. For both the events at 06:00 and 11:30 UTC, 


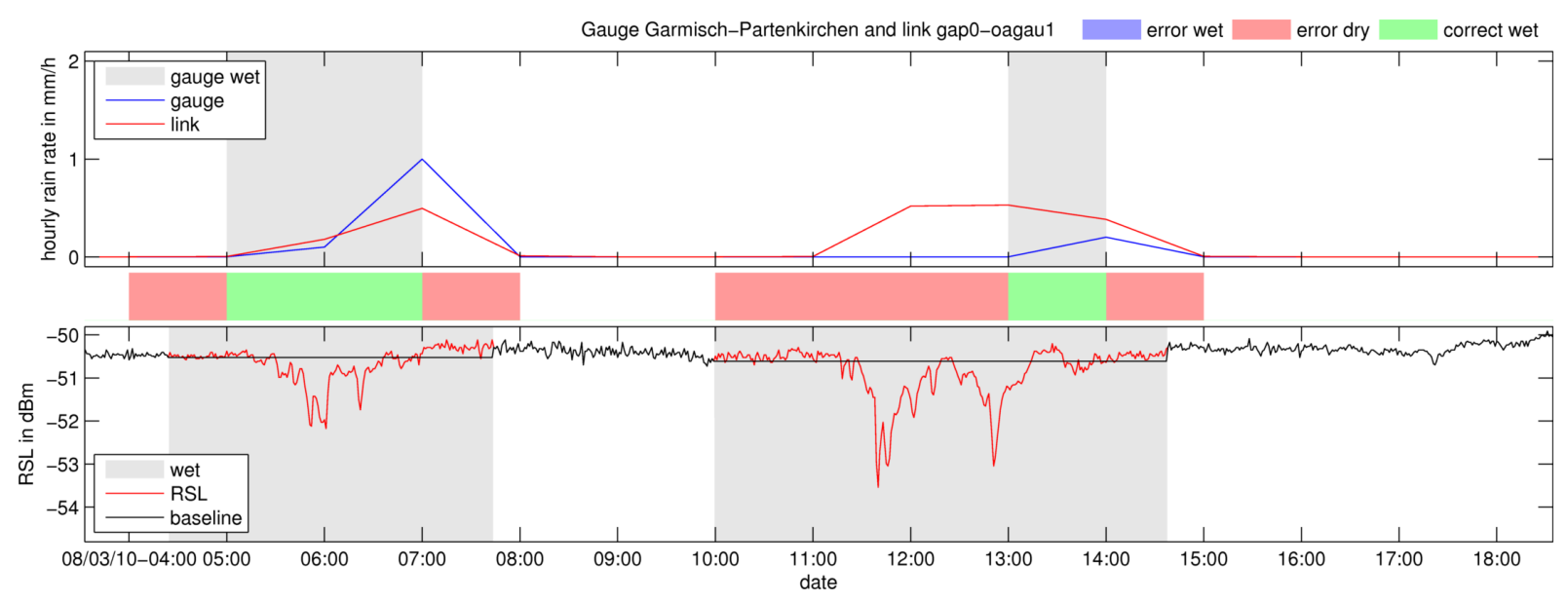

Fig. 6. Example of the limitations of the proposed wet/dry classification algorithm. Shown are time series of the minute resolution RSL data from the link gap0-gap4 (bottom plot in red), the hourly link-derived rain rate (top plot in red) and the hourly rain rate from the gauge Garmisch-Partenkirchen. Note: the hourly data are derived according to the DWD standard (e.g. 12:00 UTC mean value is averaged from 10:50 to 11:50 UTC) and the classification of a period as wet or dry applies for the whole hour before the value's timestamp (e.g. from 11:00 to 12:00 UTC for the 12:00 UTC value). The colours indicating the errors correspond to the hourly data.

a wet period is detected already one hour before and after the actual attenuation event. The cause for this broadening of the wet detection period is that the 256 min sliding window used for the spectra calculation sees large attenuation peaks 128 points (i.e. $128 \mathrm{~min}$ ) before and after the period it classifies. The effect is mitigated by the use of the Hamming window weakening the influence from the points at the window edges, but not enough. Remedy could be found by shortening the window length, but as discussed in Sect. 6.4 this would implicate other drawbacks. Although the derived rain rates for the wrongly classified period are negligible because there is almost no attenuation, this still increases the error rate. The obvious solution, weighting the detection errors with the derived rain rates to emphasise errors leading to high rain rates, is problematic. It would emphasise those dry detection errors mentioned in the previous paragraph, when a rain gauge misses a rain event clearly observed by the link.

The same limitation is visible in the example in Fig. 7. The strong attenuation event at 14:00 to 15:00 UTC also is preceded by more than one hour of wet detection without attenuation. Again, the uncertainty of the gauge as the rain event indicator for our purpose is present. Between 14:00 and 15:00 UTC, the link yields $\approx 5 \mathrm{~mm} \mathrm{~h}^{-1}$, whereas the gauge did not record any precipitation. Only the following smaller (presumably more widespread) event is detected.

Another limitation revealed by this example is the correct wet event detection for very light rain events. Starting from 01:00 UTC on the 13 August, the rain gauge at Mount Hoher Peißenberg measures five hours of very light precipitation $\left(0.1-0.2 \mathrm{~mm} \mathrm{~h}^{-1}\right)$. Looking at the RSL data of the link, a slight decrease $(\approx 1 \mathrm{~dB})$ is observable. However, the decrease takes place very slowly $\left(1 \mathrm{~dB} \mathrm{~h}^{-1}\right)$. That is, in the spectrum only the amplitudes of the lowest four frequencies (from $0.07 \times 10^{-3} \mathrm{~Hz} \widehat{=} 1 / 256$ min to $2.60 \times$ $10^{-3} \mathrm{~Hz} \hat{=} 1 / 64 \mathrm{~min}$ ) will be increased considerably by this very slow change of RSL. For the sum over all 64 low frequencies $P_{\text {sumlow }}$, their contribution is not enough to fulfil the wet period condition $P_{\text {sumlow }}-P_{\text {sumdry }}>\sigma$.

Again, this is a problem of window length. A longer window would have captured the slowly changing RSL level better, however, at the expense of detecting shorter events. Thus, a further improvement of the algorithm may be achieved using spectral analysis tools that are more suitable for revealing simultaneous changes on long and short time scales. Examples could be the discrete wavelet transform or the HilbertHuang transform (Huang et al., 1998).

Regarding RSL data sets recorded by the microwave backhaul link network providers themselves, spectral analysis tools may not always be appropriate for a wet/dry classification. Data sets may have a lower temporal resolution, e.g. $15 \mathrm{~min}$ (Overeem et al., 2011), or stronger power quantization, e.g. $1 \mathrm{~dB}$ (Goldshtein et al., 2009; Schleiss and Berne, 2010). In particular, a low temporal resolution would limit the applicability of the method proposed here. A data set sampled each 15 min (i.e. at $\approx 1 \times 10^{-3} \mathrm{~Hz}$ ) will not contain frequencies below $\approx 5 \times 10^{-4} \mathrm{~Hz}$. Hence, the important frequency range between $2 \times 10^{-3} \mathrm{~Hz}$ and $5 \times 10^{-4} \mathrm{~Hz}$ (i.e. the range of optimal values for $f_{\text {divide }}$ ) cannot be resolved. However, with the growing popularity of commercial microwave links as remote sensing tool, the availability of high resolution RSL data directly from the providers can be expected to increase. 


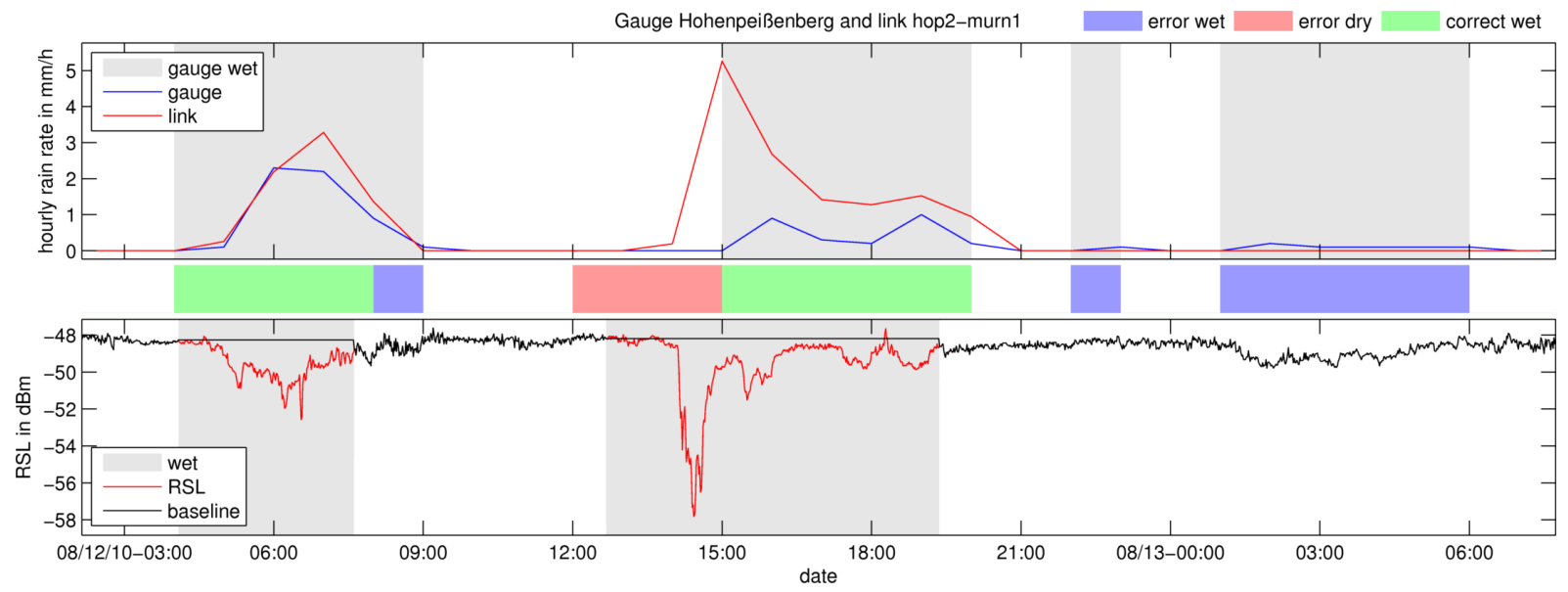

Fig. 7. Same plots as in Fig. 6 but for the link hop2-murn1 and gauge Hoher Peißenberg.

\section{Intercomparison of link-, gauge- and radar-derived rain rates}

Section 6 focused on the rain event detection, which is necessary to determine a RSL baseline. For the application of microwave links as a precipitation remote sensing tool, the crucial parameter is the rain rate it delivers. We derived rain rates by applying the algorithm introduced above with the values listed in Table 4 and the power law relation in Eq. (1). Continuous minute resolution data of RSL records are used throughout the period from July 2010 to October 2010 for all links except for gap0-gap4, where two failures of the data acquisition system made several hours of data unusable. The rain rates are then averaged hourly to be comparable with the available rain gauge and radar measurements.

\subsection{Microwave link - rain gauge comparison}

Figure 8 gives an overview of the comparison between the hourly rain rate from each of the five links and their closest rain gauge. The sixth plot on the lower right shows data from the link gap0-gap4 and the three gauges along the slope of Mount Wank beneath the link.

Correlation between the links and the DWD gauges differs from link to link between $R^{2}=0.61$ and $R^{2}=0.81$. A comparison of gap0-gap4 with our own gauges directly beneath the link on the slope of Mount Wank instead of the DWD gauge does not provide any further improvement. A look at the time series (not shown here) revealed that some events not recorded by the DWD gauge were detected by the gauges at the higher elevations (which can be attributed to precipitation generation due to orographic lifting), but the overall correlation even declined. The advantage of the better spatial representativeness might have been outweighed by the errors attributed to the steep orography and the forest cover at the gauge locations.
In general for all links, problems in the range of small rain rates can be observed, especially along the axes. The values directly on the axes (i.e. the rain gauge or the link measures zero rainfall but the respective other measurement yields a rain rate greater than zero) stem from the classification errors mentioned in Sect. 6.5. The dry detection errors lead to values on the $\mathrm{x}$-axis, wet detection errors to values on the y-axis.

For all links, except gap0-oagaul, an overestimation of rain rates is observable, with the mean link rain rate being up to twice the gauge rain rate. Besides the uncertainty of the gauges, this can be due to the uncertainty of the a- and b-values from the power law in Eq. (1) which are not specifically adapted to the rainfall climatology (that is the prevailing DSD type). Furthermore, the non-linearity of the power law leads to overestimation of rain rates because of the heterogeneity of rainfall along the links. This effect increases with lower frequencies (below $\approx 30 \mathrm{GHz}$ ) and increasing link length. The observed overestimation for the five links can however not be explained by these effects alone. It is noted that the link with the highest frequency, gap0-oagaul ( $f=23 \mathrm{GHz}$ ), yields almost no overestimation though. A further crucial effect leading to overestimation is the additional attenuation introduced by the water film present on the antenna during a rain event. We are aware of the fact that correction methods for the wet antenna effect exist (Kharadly and Ross, 2001; Minda and Nakamura, 2005; Leijnse et al., 2008; Overeem et al., 2011), but all implicate further uncertainties. Hence, as long as no reliable ground truth for the absolute rain rates along the links and information on the antenna radome type is available, we prefer not to apply a wet antenna correction.

\subsection{Microwave link - weather radar comparison}

For the two links connecting Mount Hoher Peißenberg with the cities of Weilheim and Murnau, radar data are available 

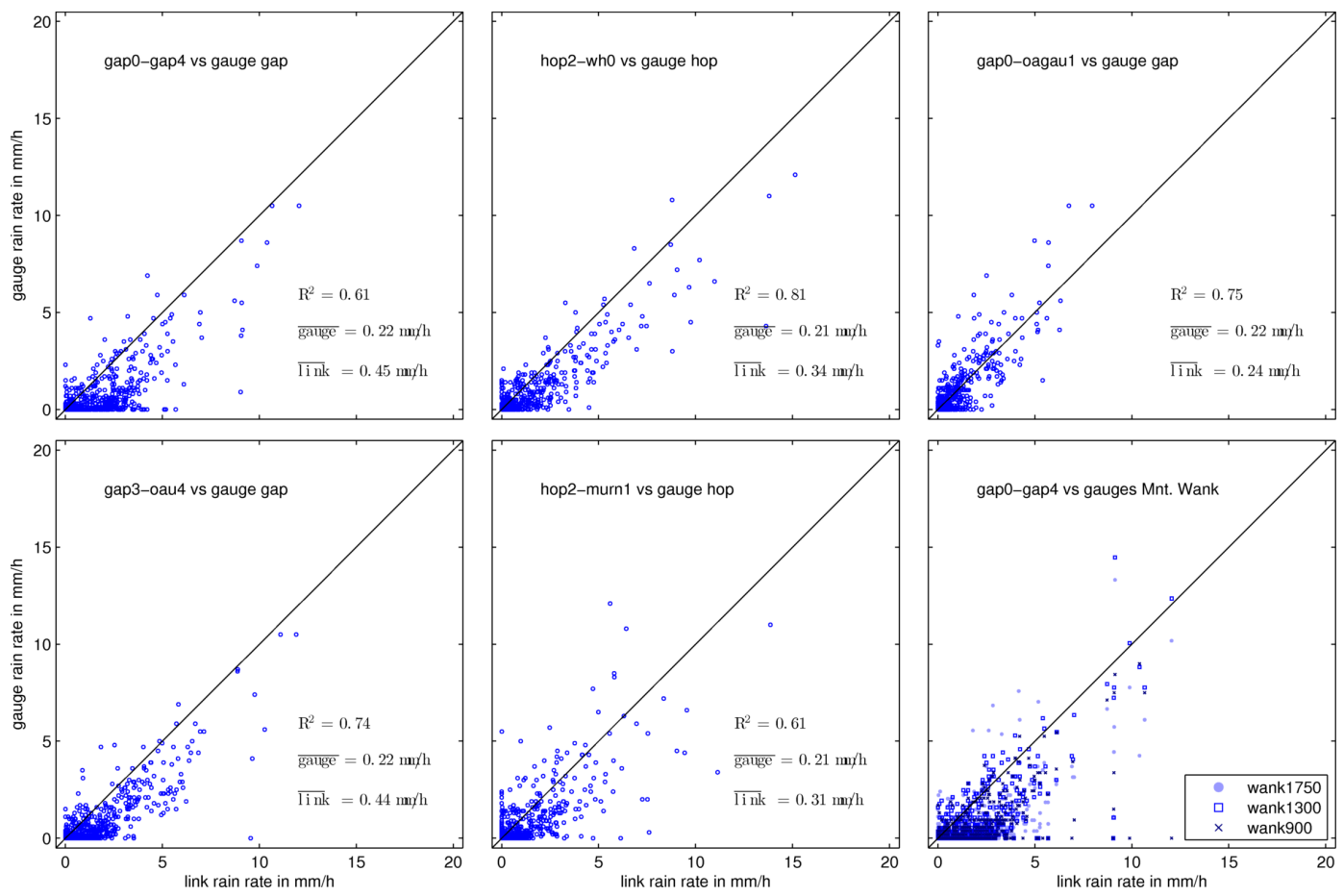

Fig. 8. Scatter plots for continuous hourly microwave link rain rate observation and DWD rain gauge data for the period from July 2010 to October 2010. The plot on the bottom right shows gauge data from the rain gauges at different altitudes on Mount Wank directly beneath the link path.
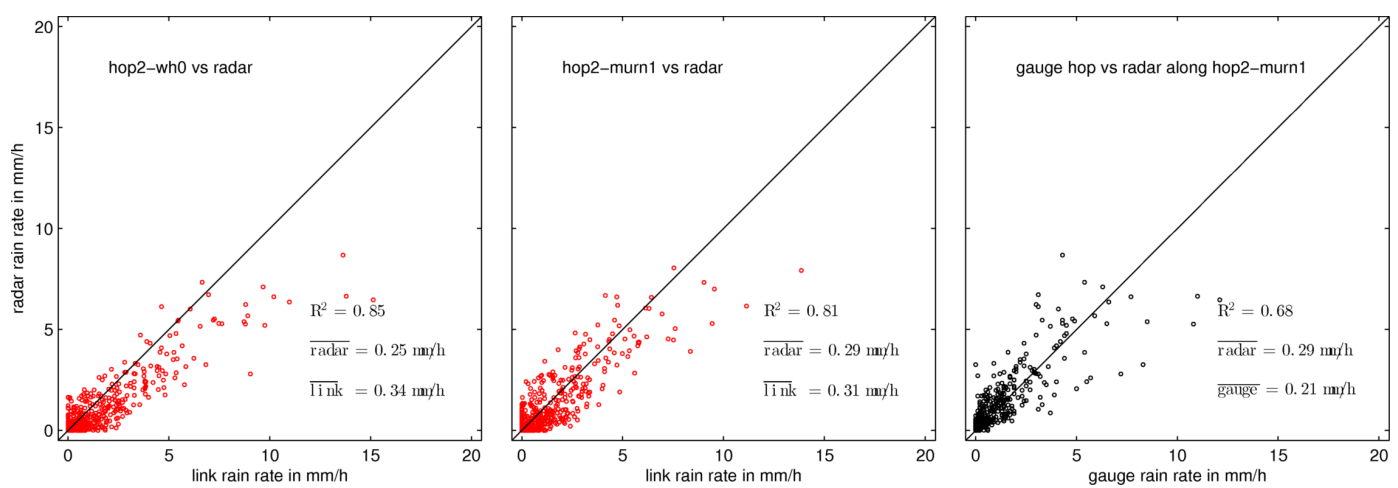

Fig. 9. Scatter plots for continuous hourly microwave link rain rate observation and DWD weather radar data along the links for the period from July 2010 to October 2010. The plot on the right gives a comparison of data from the rain gauge at Mount Hoher Peißenberg and the radar along the link hop $2-w h 0$.

throughout the test period. The radar data are processed according to the description in Sect. 4.3 and setting rain rates less than $0.1 \mathrm{~mm} \mathrm{~h}^{-1}$ to zero. The results are then averaged along the corresponding link path. Each pixel is attributed a weight based on the fraction of link length passing through it. Figure 9 shows the resulting rain rates for link and radar as well as a comparison of the gauge at Mount Hoher Peißenberg with the radar path average data along the link towards Weilheim.

In comparison with the gauge-link correlation from Fig. 8, a significant improvement can be observed for the link hop2-murn1, as $R^{2}$ increases from 0.61 to 0.81 . There are still points along the $y$-axis indicating that the link may have missed a precipitation event, resulting from the error rate for wet detection. However, many of the dry and wet detection errors from Fig. 8 vanished. The low spatial representativeness of the gauge seemed to be a major cause for the poor performance of the long link hop2-murnl $(17.4 \mathrm{~km})$. The problem of the artefacts in the radar reflectivity field, which hampered the wet/dry classification performance analysis with the radar data, is not that severe here since the very small rain rates caused by the artefacts only have a large impact 
in the classification of wet periods. Correlation for the link hop2-wh0 also increased, from an already high $R^{2}=0.81$ to $R^{2}=0.85$. Just as for the link hop2-murnl, the main improvement can be observed when the gauge seemed to have underestimated or completely missed rain events. Overestimation of the links is also less severe here.

The comparison of the gauge rain rates against the averaged radar rain rates along the link hop2-murnl (shown on the right in Fig. 9) emphasises the problem of rain gauge measurements. For low rain rates the error is small, but with higher rain rates, which mostly occur on smaller horizontal scales, the error increases. Radar rain rate availability is thus desired for our whole test region.

\section{Conclusions}

We have analysed four months of continuous RSL data from five commercial backhaul links in the pre-alpine and alpine region of Southern Germany. To derive rain rates from these data, a classification into wet and dry periods had to be performed to account for fluctuations during dry conditions. To do so, we introduced a new classification algorithm using short-time Fourier transform. It is based on the fact that spectra of wet periods, in contrast to dry periods with strong fluctuations, exhibit a significant deviation from mean dry spectra in the low frequency regime. To decide whether a period is wet or dry, sums of spectral amplitudes are compared against a threshold. Using rain gauge data (and, where possible, also radar data) as ground truth, optimal values for the threshold $\sigma$ and the spectrum division frequency $f_{\text {divide }}$ could be identified for the five links. Analysis showed that error rates are still near the optimum if $f_{\text {divide }}$ is derived from the link length and a constant $\sigma=1$ is used.

Misclassifications of the presented wet/dry classification algorithm are partly due to the low spatial representativeness of rain gauge measurements and limitations of the classification algorithm in detecting the different types of rain events (short and strong, long lasting and weak).

Using the near optimal values $f_{\text {divide }}$ determined by the link length and a constant threshold $\sigma=1$, rain rates were derived throughout the entire four-month test period. Good correlation (up to $R^{2}=0.81$ ) was found between link and rain gauge data. Using radar data averaged along the links, correlation could be improved showing that rain gauge data might not always be the best ground truth for microwave link studies. In summary, our study confirmed that commercial microwave links can be used to continuously measure rain rates over complex terrain in summer and autumn conditions.

For a further improvement of the wet/dry classification algorithm (especially for the simultaneous detection of short and long events), spectral analysis tools different from Fourier transform may be considered. The determination of $f_{\text {divide }}$ from the link length should also be further investigated. A more detailed analysis exploiting a larger number of links and taking into account link frequency, altitude and in particular wind speed and direction could provide useful additional information. With detailed knowledge of the relation of $f_{\text {divide }}$ and $\sigma$ on the given link parameters, the need for error-prone ground truthing could be avoided. This is especially important for potential future applications, e.g. in developing countries where ground truth sources are scarce. Furthermore, the algorithm's performance for longer time series spanning over all seasons should be investigated. For example, winter conditions with sleet, snow and antenna icing will pose further challenges.

Where radar-, gauge- and link measurements are available, a merging of all three data sources may provide the opportunity to obtain improved spatio temporal distributions of rainfall for all kinds of hydrological analyses.

Acknowledgements. This work was funded by the Helmholtz Association of German Research Centres under grant VH-VI-314 entitled "Regional Precipitation Observation by Cellular Network Microwave Attenuation and Application to Water Resources Management" (PROCEMA). The authors want to thank Josef Aigner from Ericsson $\mathrm{GmbH}$ for his efforts to expedite the installation of the data logger modules. TERENO (http://www.tereno.net) infrastructure is gratefully acknowledged.

The service charges for this open access publication have been covered by a Research Centre of the Helmholtz Association.

Edited by: R. Uijlenhoet

\section{References}

Andrieu, H., Creutin, J. D., Delrieu, G., and Faure, D.: Use of a weather radar for the hydrology of a mountainous area. Part I: Radar measurement interpretation, J. Hydrol., 193, 1-25, 1997.

Atlas, D.: Advances in radar meteorology, Adv. Geophys., 10, p. 385, 1964.

Atlas, D. and Ulbrich, C. W.: Path- and area-integrated rainfall measurement by microwave attenuation in the $1-3 \mathrm{~cm}$ band, J. Appl. Meteorol., 16, 1322-1331, 1977.

Bartels, H., Weigl, E., Reich, T., Lang, P., Wagner, A., Kohler, O., and Gerlach, N.: Abschlussbericht projekt RADOLAN, Tech. rep., Deutscher Wetterdienst, Offenbach, 2004.

David, N., Alpert, P., and Messer, H.: Technical Note: Novel method for water vapour monitoring using wireless communication networks measurements, Atmos. Chem. Phys., 9, 24132418, doi:10.5194/acp-9-2413-2009, 2009.

Gmeiner, A.: Interface for Procema Site Overview, available at: http://195.37.187.138/interface/map (last access: 10 January 2012), 2011.

Goldshtein, O., Messer, H., and Zinevich, A.: Rain rate estimation using measurements from commercial telecommunications links, IEEE T. Signal Proces., 57, 1616-1625, doi:10.1109/TSP.2009.2012554, 2009.

Hazenberg, P., Leijnse, H., and Uijlenhoet, R.: Radar rainfall estimation of stratiform winter precipitation in the 
Belgian Ardennes, Water Resour. Res., 47, W02507, doi:10.1029/2010WR009068, 2011

Ho, C. M., Wang, C., Angkasa, K., and Gritton, K.: Estimation of microwave power margin losses due to Earth's atmosphere and weather in the frequency range of 3-30 GHz, Tech. rep., Jet Propulsion Laboratory, Pasadena, 2004.

Holt, A., Kuznetsov, G., and Rahimi, A.: Comparison of the use of dual-frequency and single-frequency attenuation for the measurement of path-averaged rainfall along a microwave link, IET Microw. Antenna P., 150, 315-20, doi:10.1049/ipmap:20030616, 2003.

Huang, N. E., Shen, Z., Long, S. R., Wu, M. C., Shih, H. H., Zheng, Q., Yen, N., Tung, C. C., and Liu, H. H.: The empirical mode decomposition and the Hilbert spectrum for nonlinear and non-stationary time series analysis, P. Roy. Soc. A-Math. Phy., 454, 903-995, 1998.

ITU: ITU-R P.838-2: Specific Attenuation Model for Rain for Use in Prediction Methods, International Telecommunication Union, Geneva, 2003.

Joss, J. and Pittini, A.: Real-Time Estimation of the Vertical Profile of Radar Reflectivity to Improve the Measurement of Precipitation in an Alpine Region, Meteorol. Atmos. Phys. 47, 61-72, doi:10.1007/BF01025828, 1991

Kharadly, M. and Ross, R.: Effect of wet antenna attenuation on propagation data statistics, IEEE T. Antenn Propag., 49, 11831191, doi:10.1109/8.943313, 2001.

László, F. T.: Ftp2Me - The FTP client library for handheld devices, available at: http://ftp2me.sourceforge.net/ (last access: 10 January 2012), 2011.

Leijnse, H., Uijlenhoet, R., and Stricker, J. N. M.: Hydrometeorological application of a microwave link: 2. Precipitation, Water Resour. Res., 43, W04417, doi:10.1029/2006WR004989, 2007a.

Leijnse, H., Uijlenhoet, R., and Stricker, J. N. M.: Rainfall measurement using radio links from cellular communication networks, Water Resour. Res., 43, W03201, doi:10.1029/2006WR005631, $2007 b$

Leijnse, H., Uijlenhoet, R., and Stricker, J.: Microwave link rainfall estimation: effects of link length and frequency, temporal sampling, power resolution, and wet antenna attenuation, Adv. Water Resour., 31, 1481-1493, doi:10.1016/j.advwatres.2008.03.004, 2008.

Liebe, H. J.: MPM - an atmospheric millimeter-wave propagation model, Int. J. Infrared Milli., 10, 631-650, 1989.

Messer, H., Zinevich, A., and Alpert, P.: Environmental monitoring by wireless communication networks, Science, 312, 5774, doi:10.1126/science.1120034, 2006.

Minda, H. and Nakamura, K.: High temporal resolution pathaverage rain gauge with $50-\mathrm{GHz}$ band microwave, J. Atmos. Ocean. Tech., 22, 165-179, 2005.

Mueller, G.: Propagation of 6-millimeter waves, P. IRE, 34, 181183, doi:10.1109/JRPROC.1946.234240, 1946.

Nešpor, V. and Sevruk, B.: Estimation of wind-induced error of rainfall gauge measurements using a numerical simulation, J. Atmos. Ocean. Tech., 16, 450-464, doi:10.1175/15200426(1999)016<0450:EOWIEO>2.0.CO;2, 1999.

Olsen, R., Rogers, D., and Hodge, D.: The $a R^{b}$ Relation in the calculation of rain attenuation, IEEE T. Antenn. Propag., 26, 318329, 1978.
Overeem, A., Leijnse, H., and Uijlenhoet, R.: Measuring urban rainfall using microwave links from commercial cellular communication networks, Water Resour. Res., 47, W12505, doi:10.1029/2010WR010350, 2011.

Rahimi, A. R., Holt, A. R., Upton, G. J. G., and Cummings, R. J.: Use of dual-frequency microwave links for measuring path-averaged rainfall, J. Geophys. Res.-Atmos., 108, 4467, doi:10.1029/2002JD003202, 2003.

Rahimi, A. R., Upton, G. J. G., and Holt, A. R.: Dual-frequency links - a complement to gauges and radar for the measurement of rain, J. Hydrol., 288, 3-12, doi:10.1016/j.jhydrol.2003.11.008, 2004.

Rayitsfeld, A., Samuels, R., Zinevich, A., Hadar, U., and Alpert, P.: Comparison of two methodologies for long term rainfall monitoring using a commercial microwave communication system, Atmos. Res., 104-105, 119-127, doi:10.1016/j.atmosres.2011.08.011, 2012.

Rincon, R. F. and Lang, R. H.: Microwave link dual-wavelength measurements of path-average attenuation for the estimation of drop size distributions and rainfall, IEEE T. Geosci. Remote, 40, 760-770, 2002.

Ruf, C. S., Aydin, K., Mathur, S., and Bobak, J. P.: 35-GHz dualpolarization propagation link for rain-rate estimation, J. Atmos. Ocean. Tech., 13, 419-425, 1996.

Schleiss, M. and Berne, A.: Identification of dry and rainy periods using telecommunication microwave links, IEEE Geosci. Remote S., 7, 611-615, doi:10.1109/LGRS.2010.2043052, 2010.

Sevruk, B. and Zahlavova, L.: Classification system of precipitation gauge site exposure: evaluation and application, Int. J. Climatol., 14, 681-689, doi:10.1002/joc.3370140607, 1994.

Stratton, J.: The effect of rain and fog on the propagation of very short radio waves, P. IRE, 18, 1064-1074, doi:10.1109/JRPROC.1930.222101, 1930.

Townsend, A. J. and Watson, R. J.: The linear relationship between attenuation and average rainfall rate for terrestrial links, IEEE T. Antenn. Propag., 59, 994-1002, doi:10.1109/TAP.2010.2103021, 2011.

Ulbrich, C. W. and Lee, L. G.: Rainfall measurement error by WSR-88D radars due to variations in Z$\mathrm{R}$ law parameters and the radar constant, J. Atmos. Ocean. Tech., 16, 1017-1024, doi:10.1175/15200426(1999)016<1017:RMEBWR > 2.0.CO;2, 1999.

Upton, G., Holt, A., Cummings, R., Rahimi, A., and Goddard, J.: Microwave links: the future for urban rainfall measurement?, Atmos. Res., 77, 300-312, doi:10.1016/j.atmosres.2004.10.009, 2005.

Valtr, P., Pechac, P., Kvicera, V., and Grabner, M.: Estimation of the refractivity structure of the lower troposphere from measurements on a terrestrial multiple-receiver radio link, IEEE T. Antenn. Propag., 59, 1707-1715, doi:10.1109/TAP.2011.2122234, 2011.

Zinevich, A., Alpert, P., and Messer, H.: Estimation of rainfall fields using commercial microwave communication networks of variable density, Adv. Water Resour., 31, 1470-1480, doi:10.1016/j.advwatres.2008.03.003, 2008.

Zinevich, A., Messer, H., and Alpert, P.: Prediction of rainfall intensity measurement errors using commercial microwave communication links, Atmos. Meas. Tech., 3, 1385-1402, doi:10.5194/amt-3-1385-2010, 2010. 